\title{
SYARAT CUKUP KEKONVERGENAN METODE NEWTON-RAPHSON
}

\author{
DEVI SARI RAMADHINI, MAHDHIVAN SYAFWAN, JENIZON \\ Program Studi S1 Matematika, \\ Fakultas Matematika dan Ilmu Pengetahuan Alam, Universitas Andalas, \\ Kampus UNAND Limau Manis Padang, Indonesia. \\ email : devisariramadhini@yahoo.com
}

Diterima 22 Juni 2019 Direvisi 6 Juli 2019 Dipublikasikan 4 Agustus 2019

\begin{abstract}
Abstrak. Pada makalah ini akan dibahas penurunan metode Newton-Raphson. Selanjutnya diinvestigasi beberapa syarat cukup bagi kekonvergenan metode NewtonRaphson. Untuk mengilustrasikan syarat cukup kekonvergenan metode Newton-Raphson tersebut, diberikan beberapa contoh terkait.
\end{abstract}

Kata Kunci: Metode Newton-Raphson, Syarat cukup, Kekonvergenan

\section{Pendahuluan}

Salah satu masalah matematika yang sering ditemui yaitu menentukan penyelesaian dari persamaan nonlinier. Persamaan nonlinier seringkali tidak dapat diselesaikan secara analitik, sehingga digunakan metode numerik. Salah satu metode numerik yang sering digunakan yaitu metode iterasi. Metode ini diharapkan dapat menghasilkan suatu barisan solusi yang konvergen ke solusi eksak dari persamaan tersebut. Salah satu metode iterasi yang paling sering digunakan adalah metode NewtonRaphson. Konsep dasar dari metode Newton-Raphson diperkenalkan pertama kali oleh Isaac Newton dalam bukunya yang berjudul "De Analyst per Aequationes Infinitas" (1669) [7]. Namun sebelum Newton, ide dari metode yang analog dengan metode ini ternyata juga ditemukan pada naskah yang ditulis oleh matematikawan Arab yang bernama Al-Kasi pada abad ke-15 [7]. Pada tahun 1690, Joseph Raphson menjelaskan metode yang dikembangkan oleh Newton tersebut dengan cara yang lebih sistematis [7]. Metode inilah yang saat ini dikenal dengan sebutan metode Newton-Raphson [3].

Secara umum, metode Newton-Raphson dalam menyelesaikan persamaan nonlinier $f(x)=0$ mempunyai rumus iterasi sebagai berikut:

$$
\phi\left(x^{(n)}\right)=x^{(n+1)}=x^{(n)}-\frac{f\left(x^{(n)}\right)}{f^{\prime}\left(x^{(n)}\right)}, n=0,1,2, \cdots,
$$

dengan suatu tebakan awal $x^{(0)}$ [4]. Pada dasarnya tidak dapat dipastikan bahwa persamaan (1.1) akan menghasilkan barisan $\left\{x^{(n)}\right\}$ yang konvergen ke solusi $x^{*}$ 
174 Devi Sari Ramadhini dkk

(yaitu $f\left(x^{*}\right)=0$ ). Oleh karena itu, perlu diselidiki apa saja syarat yang menjamin barisan $\left\{x^{(n)}\right\}$ akan konvergen ke solusi $x^{*}$.

\section{Landasan Teori}

\subsection{Kekonsistenan}

Persamaan $x=\phi(x)$ dan $f(x)=0$ pada pembahasan sebelumnya belum tentu mempunyai solusi yang sama. Oleh karena itu perlu didefinisikan konsep berikut.

Definisi 2.1. [3] Fungsi iterasi $\phi(x)$ dikatakan konsisten (consistent) terhadap persamaan $f(x)=0$, jika solusi dari $f(x)=0$ juga merupakan solusi dari $\phi(x)=x$. Fungsi iterasi $\phi(x)$ dikatakan konsisten timbal balik (reciprocally consistent) terhadap persamaan $f(x)=0$, jika solusi dari $\phi(x)=x$ juga merupakan solusi dari $f(x)=0$. Fungsi iterasi $\phi(x)$ dikatakan konsisten seutuhnya (completely consistent) terhadap persamaan $f(x)=0$, jika $\phi(x)=x$ konsisten dan konsisten timbal balik terhadap persamaan $f(x)=0$.

\subsection{Kekonvergenan}

Barisan $\left\{x^{(n)}\right\}$ yang diperoleh dari persamaan (1.1) tidak dapat langsung dipastikan akan konvergen ke solusi $x^{*}$. Dengan demikian dibutuhkan penyelidikan mengenai syarat cukup bagi metode iterasi untuk konvergen ke solusi $x^{*}$. Sebelum membahas kekonvergenan metode iterasi, dijelaskan terlebih dahulu definisi dan teorema pendukung berikut ini.

Teorema 2.2. [1] Jika $f$ adalah fungsi kontinu pada interval tutup $I=[a, b]$ dan mempunyai turunan pada interval buka $(a, b)$, maka terdapat suatu titik $c \in(a, b)$ sedemikian sehingga

$$
f^{\prime}(c)=\frac{f(b)-f(a)}{b-a}
$$

Definisi 2.3. [1] Barisan $X=\left\{x^{(n)}\right\}$ pada $\mathbb{R}$ disebut barisan Cauchy, jika untuk setiap $\varepsilon>0$ terdapat suatu bilangan asli $N_{\varepsilon}$ sedemikian sehingga untuk semua $n, m \geqslant N_{\varepsilon}$ memenuhi $\left|x^{(n)}-x^{(m)}\right|<\varepsilon$.

Teorema 2.4. [1] Suatu barisan $\left\{x^{(n)}\right\}$ pada $\mathbb{R}$ konvergen jika dan hanya jika $\left\{x^{(n)}\right\}$ barisan Cauchy.

Definisi 2.5. [1] Suatu barisan $\left\{x^{(n)}\right\}$ pada $\mathbb{R}$ disebut barisan kontraktif jika terdapat $0<c<1$, sedemikian sehingga

$$
\left|x^{(n+2)}-x^{(n+1)}\right| \leqslant c\left|x^{(n+1)}-x^{(n)}\right|
$$

untuk setiap $n \in \mathbb{N}$.

Teorema 2.6. [1] Setiap barisan kontraktif adalah barisan Cauchy sehingga barisannya konvergen.

Syarat cukup kekonvergenan metode iterasi diberikan oleh teorema berikut. 
Teorema 2.7. [5] Misalkan $\phi(x): \mathbb{R} \rightarrow \mathbb{R}$, terdapat suatu $0<c<1$ sedemikian sehingga

$$
\left|\phi\left(x^{(n+1)}\right)-\phi\left(x^{(n)}\right)\right|<c\left|x^{(n+1)}-x^{(n)}\right|
$$

untuk $n=0,1,2, \cdots$ dimana $x^{(0)} \in I$ dan $\phi(I) \subset I$, maka barisan $x^{(0)}, x^{(1)}, x^{(2)}, \cdots$ yang diperoleh dari persamaan (1.1) konvergen ke $x^{*} \in I$ yang memenuhi $x^{*}=$ $\phi\left(x^{*}\right)$.

\subsection{Fungsi Naik dan Fungsi Turun}

Fungsi naik dan fungsi turun didefinisikan sebagai berikut.

Definisi 2.8. [1] Fungsi $f: A \longrightarrow \mathbb{R}$ disebut fungsi naik pada interval I jika untuk setiap $x_{1}, x_{2} \in I$ dimana $x_{1}<x_{2}$, maka $f\left(x_{1}\right) \leqslant f\left(x_{2}\right)$. Fungsi $f$ disebut fungsi naik sejati pada interval $I$ jika untuk setiap $x_{1}, x_{2} \in I$ dimana $x_{1}<x_{2}$, maka $f\left(x_{1}\right)<f\left(x_{2}\right)$. Selain itu, fungsi $g: A \longrightarrow \mathbb{R}$ disebut fungsi turun pada interval $I$ jika untuk setiap $x_{1}, x_{2} \in I$ dimana $x_{1}<x_{2}$, maka $g\left(x_{1}\right) \geqslant g\left(x_{2}\right)$. Fungsi $g$ disebut fungsi turun sejati pada interval I jika untuk setiap $x_{1}, x_{2} \in I$ dimana $x_{1}<x_{2}$, maka $g\left(x_{1}\right)>g\left(x_{2}\right)$.

Teorema berikut memberikan kriteria fungsi naik dan fungsi turun.

Teorema 2.9. [2] Jika $f$ kontinu pada interval I, maka:

(i) Jika $f^{\prime}(x) \geqslant 0$ untuk setiap $x \in I$, maka $f$ adalah fungsi naik. Jika $f^{\prime}(x)>0$ untuk setiap $x \in I$, maka $f$ adalah fungsi naik sejati.

(ii) Jika $f^{\prime}(x) \leqslant 0$ untuk setiap $x \in I$, maka $f$ adalah fungsi turun. Jika $f^{\prime}(x)<0$ untuk setiap $x \in I$, maka $f$ adalah fungsi turun sejati.

\section{Pembahasan}

\subsection{Penurunan Metode Newton-Raphson}

Fungsi iterasi dari metode Newton-Raphson dengan suatu tebakan awal dapat diilustrasikan seperti pada Gambar 1. Berdasarkan Gambar 1 dapat diperoleh fungsi

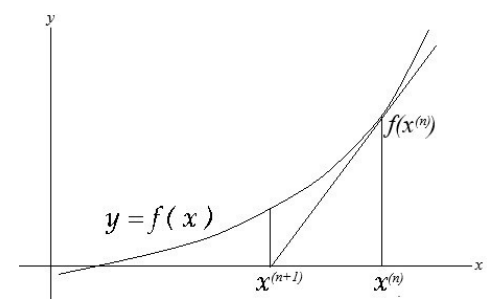

Gambar 1. Ilustrasi Penurunan Metode Newton-Raphson

iterasi metode Newton-Raphson dengan langkah-langkah berikut [6]: 
(a) Misalkan terdapat suatu tebakan awal $x^{(n)}$ untuk $n=0,1,2 \cdots$

(b) Misalkan $f^{\prime}(x)$ adalah gradien garis singgung kurva $y=f(x)$ di titik $\left(x^{(n)}, f\left(x^{(n)}\right)\right.$, maka akan diperoleh persamaan garis singgungnya, yakni $y=$ $f^{\prime}\left(x^{(n)}\right)\left(x-x^{(n)}\right)+f\left(x^{(n)}\right)$.

(c) Hampiran selanjutnya merupakan absis titik potong garis singgung tersebut dengan sumbu- $x$. Pada Gambar 3.1.1 terlihat bahwa untuk $x=x^{(n+1)}$, nilai ordinat dari garis singgung adalah $y=0$, sehingga dapat diperoleh

$$
x^{(n+1)}=x^{(n)}-\frac{f\left(x^{(n)}\right)}{f^{\prime}\left(x^{(n)}\right)} .
$$

(d) Persamaan (3.1) merupakan rumus iterasi metode Newton-Raphson. Dengan demikian fungsi iterasi dari metode Newton-Raphson diberikan oleh

$$
\phi(x)=x-\frac{f(x)}{f^{\prime}(x)} .
$$

Adapun kekurangan dari metode Newton-Raphson adalah fungsi $f$ harus diketahui turunannya, sementara tidak semua fungsi dapat diturunkan dengan mudah. Selain itu juga diperlukan suatu tebakan awal $x^{(0)}$ yang tepat agar barisan $\left\{x^{(n)}\right\}$ yang dihasilkan konvergen ke solusi eksaknya. Kriteria penghentian iterasi yang dapat dipakai pada metode Newton-Raphson adalah $\left|x^{(n+1)}-x^{(n)}\right|<\epsilon$, dimana $\epsilon$ adalah batas galat yang diberikan. Kekonsistenan pada metode Newton-Raphson dijelaskan pada teorema berikut.

Teorema 3.1. Fungsi iterasi $\phi(x)$ pada metode Newton-Raphson konsisten seutuhnya (completely consistent) terhadap persamaan $f(x)=0$.

Bukti. Fungsi iterasi $\phi(x)$ dikatakan konsisten seutuhnya (completely consistent) terhadap persamaan $f(x)=0$, jika $\phi(x)=x$ konsisten dan konsisten timbal balik terhadap persamaan $f(x)=0$, atau dengan kata lain $f(x)=0$ jika dan hanya jika $\phi(x)=x$.

Terlebih dahulu akan dibuktikan jika $f(x)=0$ maka $\phi(x)=x$. Misalkan $f(x)=0$, maka

$$
\phi(x)=x-\frac{f(x)}{f^{\prime}(x)}=x .
$$

Selanjutnya akan dibuktikan jika $\phi(x)=x$ maka $f(x)=0$. Misalkan $\phi(x)=x$, maka

$$
\begin{aligned}
& \phi(x)=x-\frac{f(x)}{f^{\prime}(x)} \\
& \Longleftrightarrow \quad x=x-\frac{f(x)}{f^{\prime}(x)} \\
& \Longleftrightarrow \quad x-x=-\frac{f(x)}{f^{\prime}(x)} \\
& \Longleftrightarrow \quad 0=f(x) .
\end{aligned}
$$

Dengan demikian terbukti bahwa fungsi iterasi $\phi(x)$ pada metode Newton-Raphson konsisten seutuhnya (completely consistent) terhadap persamaan $f(x)=0$. 


\subsection{Syarat Cukup Kekonvergenan Metode Newton-Raphson}

Ada beberapa teorema yang memberikan syarat cukup kekonvergenan metode Newton-Raphson. Berikut ini akan dibahas beberapa teorema tersebut beserta buktinya.

Teorema 3.2. [3] Misalkan $f(x)$ mempunyai turunan yang kontinu, $f(x)$ adalah fungsi naik sejati dan $f^{\prime}(x)$ adalah fungsi naik pada interval $\left[x^{*}, x^{(0)}\right]$ dan $f^{\prime}(x) \neq 0$ untuk setiap $x \in\left[x^{*}, x^{(0)}\right]$, maka metode Newton-Raphson dengan tebakan awal $x^{(0)}$ akan konvergen ke $x^{*}$.

Bukti. Misalkan $f(x)$ adalah fungsi naik sejati, $f^{\prime}(x)$ adalah fungsi naik pada interval $\left[x^{*}, x^{(0)}\right]$ dan $f^{\prime}(x) \neq 0$ untuk setiap $x \in\left[x^{*}, x^{(0)}\right]$. Akan ditunjukkan bahwa metode Newton-Raphson dengan tebakan awal $x^{(0)}$ akan konvergen ke $x^{*}$. Sebelumnya akan dibuktikan bahwa barisan $\left\{x^{(n)}\right\}$ turun dengan batas bawah $x^{*}$. Hal ini cukup dengan menunjukkan $x^{*} \leqslant x^{(1)}<x^{(0)}$. Diketahui bahwa $x^{*}<x^{(0)}$ dan $f(x)$ adalah fungsi naik sejati, maka $f\left(x^{(0)}\right)>f\left(x^{*}\right)$ dan $f^{\prime}(x)>0$. Karena $f\left(x^{*}\right)=0$, maka $f\left(x^{(0)}\right)>0$. Lebih lanjut, $f^{\prime}\left(x^{(0)}\right) \neq 0$. Dengan demikian $0<$ $\frac{f\left(x^{(0)}\right)}{f^{\prime}\left(x^{(0)}\right)}$, sehingga dapat diperoleh

$$
x^{(1)}=x^{(0)}-\frac{f\left(x^{(0)}\right)}{f^{\prime}\left(x^{(0)}\right)}<x^{(0)} .
$$

Berdasarkan Teorema 2.2, terdapat suatu $\xi \in\left[x^{*}, x^{(0)}\right]$ sedemikian sehingga $f\left(x^{(0)}\right)=f^{\prime}(\xi)\left(x^{(0)}-x^{*}\right)$. Karena $f^{\prime}(x)$ fungsi naik, maka $f^{\prime}(\xi) \leqslant f^{\prime}\left(x^{(0)}\right)$. Akibatnya

$$
\begin{aligned}
f\left(x^{(0)}\right) & =f^{\prime}(\xi)\left(x^{(0)}-x^{*}\right) \\
& \leqslant f^{\prime}\left(x^{(0)}\right)\left(x^{(0)}-x^{*}\right) \\
& \Longleftrightarrow x^{*} \leqslant x^{(0)}-\frac{f\left(x^{(0)}\right)}{f^{\prime}\left(x^{(0)}\right)}=x^{(1)}
\end{aligned}
$$

Dari hubungan (3.3) dan (3.4) terbukti bahwa $x^{*} \leqslant x^{(1)}<x^{(0)}$.

Selanjutnya akan dibuktikan bahwa tidak mungkin terdapat $x^{* *} \in\left(x^{*}, x^{(0)}\right)$ sedemikian sehingga

$$
\lim _{n \rightarrow \infty} x^{(n)}=x^{* *} \neq x^{*}
$$

Misalkan pernyataan sebelumnya berlaku. Karena $x^{* *} \in\left(x^{*}, x^{(0)}\right)$, dan $f(x)$ adalah fungsi naik sejati, maka $f\left(x^{* *}\right)>f\left(x^{*}\right)=0$ dan $f\left(x^{* *}\right) / f^{\prime}\left(x^{(0)}\right)>0$. Dengan demikian terdapat $m$ sedemikian sehingga

$$
x^{* *}<x^{(m)}<x^{* *}+\frac{f\left(x^{* *}\right)}{f^{\prime}\left(x^{(0)}\right)} .
$$

Karena $f(x)$ adalah fungsi naik sejati, maka untuk $x^{* *}<x^{(m)}$ berlaku $f\left(x^{* *}\right)<$ $f\left(x^{(m)}\right)$. Selanjutnya karena $f^{\prime}(x)$ adalah fungsi naik, maka untuk $x^{(0)} \geqslant x^{(m)}$ 
berlaku $f^{\prime}\left(x^{(0)}\right) \geqslant f^{\prime}\left(x^{(m)}\right)$. Dengan demikian $\frac{f\left(x^{* *}\right)}{f^{\prime}\left(x^{(0)}\right)}<\frac{f\left(x^{(m)}\right)}{f^{\prime}\left(x^{(m)}\right)}$. Jadi dapat diperoleh

$$
\begin{aligned}
x^{(m)} & <x^{* *}+\frac{f\left(x^{(m)}\right)}{f^{\prime}\left(x^{(m)}\right)} \\
& \Longleftrightarrow x^{(m)}-\frac{f\left(x^{(m)}\right)}{f^{\prime}\left(x^{(m)}\right)}<x^{* *} \\
& \Longleftrightarrow x^{(m+1)}<x^{* *} .
\end{aligned}
$$

Hasil terakhir ini kontradiksi dengan pernyataan sebelumnya. Jadi mestilah $x^{* *}=$ $x^{*}$.

Teorema 3.3. [3] Misalkan $f(x)$ mempunyai turunan yang kontinu, $f(x)$ adalah fungsi turun sejati dan $f^{\prime}(x)$ adalah fungsi turun pada interval $\left[x^{*}, x^{(0)}\right]$ dan $f^{\prime}(x) \neq$ 0 untuk setiap $x \in\left[x^{*}, x^{(0)}\right]$, maka metode Newton-Raphson dengan tebakan awal $x^{(0)}$ akan konvergen ke $x^{*}$.

Bukti. Pembuktian analog dengan pembuktian Teorema 3.2.

Teorema 3.4. [3] Jika $f(x)$ mempunyai turunan yang kontinu, dan untuk setiap $x$ yang terletak antara $x^{(0)}$ dan $x^{*}$ berlaku $f^{\prime}(x) \neq 0$ dan $f(x) f^{\prime \prime}(x)>0$, maka metode Newton-Raphson dengan tebakan awal $x^{(0)}$ akan konvergen ke $x^{*}$.

Bukti. Diketahui bahwa $x$ terletak antara $x^{(0)}$ dan $x^{*}$, maka pembuktian dapat dibagi menjadi dua kasus, yaitu

(1) Untuk $x \in\left[x^{*}, x^{(0)}\right]$. Karena $f^{\prime}(x) \neq 0$, maka pandang dua subkasus, yaitu:

(i) Jika $f^{\prime}(x)>0$, maka $f(x)$ adalah fungsi naik sejati. Karena $x^{*}$ adalah solusi, yaitu memenuhi $f\left(x^{*}\right)=0$, dan $f(x)$ adalah fungsi naik sejati di $x \in\left[x^{*}, x^{(0)}\right]$, maka $f(x)>f\left(x^{*}\right)=0$. Diketahui bahwa $f(x) f^{\prime \prime}(x)>0$, maka mestilah $f^{\prime \prime}(x)>0$. Dengan demikian $f^{\prime}(x)$ adalah fungsi naik sejati. Hal ini memenuhi kondisi pada Teorema 3.2, sehingga metode Newton-Raphson dengan tebakan awal $x^{(0)}$ akan konvergen ke $x^{*}$.

(ii) Jika $f^{\prime}(x)<0$, maka $f(x)$ adalah fungsi turun sejati. Karena $x^{*}$ adalah solusi, yaitu memenuhi $f\left(x^{*}\right)=0$, dan $f(x)$ adalah fungsi turun sejati di $x \in\left[x^{*}, x^{(0)}\right]$, maka $f(x)<f\left(x^{*}\right)=0$. Diketahui bahwa $f(x) f^{\prime \prime}(x)>0$, maka mestilah $f^{\prime \prime}(x)<0$. Dengan demikian $f^{\prime}(x)$ adalah fungsi turun sejati. Hal ini memenuhi kondisi pada Teorema 3.3. sehingga metode Newton-Raphson dengan tebakan awal $x^{(0)}$ akan konvergen ke $x^{*}$.

(2) Untuk $x \in\left[x^{(0)}, x^{*}\right]$. Karena $f^{\prime}(x) \neq 0$, maka pandang dua subkasus, yaitu:

(i) Jika $f^{\prime}(x)>0$, maka $f(x)$ adalah fungsi naik sejati. Karena $x^{*}$ adalah solusi, yaitu memenuhi $f\left(x^{*}\right)=0$, dan $f(x)$ adalah fungsi naik sejati di $x \in\left[x^{(0)}, x^{*}\right]$, maka $f(x)<f\left(x^{*}\right)=0$. Diketahui bahwa $f(x) f^{\prime \prime}(x)>0$, maka mestilah $f^{\prime \prime}(x)<0$. Dengan demikian $f^{\prime}(x)$ adalah fungsi turun sejati. Pembuktian selanjutnya analog dengan pembuktian Teorema 3.2. 
(ii) Jika $f^{\prime}(x)<0$ maka $f(x)$ adalah fungsi turun sejati. Karena $x^{*}$ adalah solusi, yaitu memenuhi $f\left(x^{*}\right)=0$ dan $f(x)$ adalah fungsi turun sejati di $x \in$ $\left[x^{(0)}, x^{*}\right]$, maka $f\left(x^{(0)}\right)>f\left(x^{*}\right)=0$. Karena $f(x) f^{\prime \prime}(x)>0$, maka mestilah $f^{\prime \prime}(x)>0$. Dengan demikian $f^{\prime}(x)$ adalah fungsi naik sejati. Pembuktian selanjutnya analog dengan pembuktian Teorema 3.2.

Jika kondisi pada Teorema 3.2, Teorema 3.3 atau Teorema 3.4 tidak terpenuhi, mungkin akan ada beberapa permasalahan yang terjadi, seperti kekonvergenan yang sangat lama atau bisa jadi tidak diperoleh solusi yang konvergen. Untuk mengilustrasikan hal ini, perhatikan beberapa contoh berikut.

Contoh 3.5. Menentukan solusi dari persamaan $e^{x}=3$ dimana menggunakan metode Newton-Raphson dengan $x^{(0)}=1.3$ dan batas galat $10^{-7}$.

Diketahui $f(x)=e^{x}-3$. Misalkan solusi dari $f(x)=0$ diberikan oleh $x^{*}$. Perhatikan bahwa $f\left(x^{(0)}\right)=f(1.3)=e^{1.3}-3>0$ dan $e^{x}-3>0$ untuk setiap $x>1.3$, maka pandang interval $\left[x^{*}, x^{(0)}\right]$. Selanjutnya dapat diperoleh $f^{\prime}(x)=e^{x} \operatorname{dan} f^{\prime}(x)$ adalah fungsi yang kontinu pada interval $\left[x^{*}, x^{(0)}\right] \subset \mathbb{R} . f(x)$ adalah fungsi naik sejati karena $f^{\prime}(x)=e^{x}>0, f^{\prime}(x)$ adalah fungsi naik sejati karena $f^{\prime \prime}(x)=e^{x}>0$ dan $f^{\prime}(x) \neq 0$ di setiap $x \in\left[x^{*}, x^{(0)}\right] \subset \mathbb{R}$. Berdasarkan Teorema 3.2 dan Teorema 3.4, maka metode Newton-Raphson dengan tebakan awal $x^{(0)}$ akan konvergen ke solusi $x^{*}$.

Contoh 3.6. Menentukan solusi dari $f(x)=x e^{-x}$ dengan menggunakan metode Newton-Raphson dimana $x^{(0)}=2$ dan batas galat $10^{-9}$.

Diketahui bahwa $f(x)=x e^{-x}$. Misalkan solusi dari $f(x)=0$ diberikan oleh $x^{*}$. Perhatikan bahwa $f\left(x^{(0)}\right)=f(2)=x e^{-x}>0$ dan $x e^{-x}>0$ untuk setiap $x>2$, maka pandang interval $\left[x^{*}, x^{(0)}\right]$. Selanjutnya dapat diperoleh $f^{\prime}(x)=e^{-x}-x e^{-x}$ dan kontinu pada interval $\left[x^{*}, x^{(0)}\right] \subset \mathbb{R}$. Namun, terdapat $x \in\left[x^{*}, x^{(0)}\right] \subset \mathbb{R}$ sedemikian sehingga $f^{\prime}(x)=0$. Hal ini tidak memenuhi syarat pada Teorema 3.3 dan Teorema 3.4.

Contoh berikut sama dengan Contoh 3.6, namun dengan tebakan awal yang berbeda.

Contoh 3.7. Menentukan solusi dari $f(x)=x e^{-x}$ dengan menggunakan metode Newton-Raphson dimana $x^{(0)}=-2$ dan batas galat $10^{-8}$.

Diketahui bahwa $f(x)=x e^{-x}$. Misalkan solusi dari $f(x)=0$ diberikan oleh $x^{*}$. Perhatikan bahwa $f\left(x^{(0)}\right)=f(-2)=x e^{-x}<0$ dan $x e^{-x}<0$ untuk setiap $x<-2$, maka pandang interval $\left[x^{(0)}, x^{*}\right]$. Selanjutnya dapat diperoleh $f^{\prime}(x)=e^{-x}-x e^{-x}$ dan kontinu pada interval $\left[x^{(0)}, x^{*}\right] \subset \mathbb{R}$. $f(x)$ fungsi naik sejati karena $f^{\prime}(x)=$ $e^{-x}-x e^{-x}>0, f^{\prime}(x)$ adalah fungsi turun sejati karena $f^{\prime \prime}(x)=-2 e^{-x}+x e^{-x}<0$ dan $f^{\prime}(x) \neq 0$ di setiap $x \in\left[x^{(0)}, x^{*}\right] \subset \mathbb{R}$. Berdasarkan Teorema 3.4, maka metode Newton-Raphson dengan tebakan awal $x^{(0)}$ akan konvergen ke solusi $x^{*}$.

Contoh 3.8. Menentukan akar positif dari $f(x)=x^{30}-1$ dengan menggunakan metode Newton-Raphson dimana $x^{(0)}=2 / 3$ dan batas galat $10^{-9}$. 
Diketahui bahwa $f(x)=x^{30}-1$. Misalkan solusi dari $f(x)=0$ diberikan oleh $x^{*}$. Perhatikan bahwa $f\left(x^{(0)}\right)=f(2 / 3)=(2 / 3)^{30}-1<0$ dan $x^{30}-1<0$ untuk setiap $0<x<2 / 3$, maka pandang interval $\left[x^{(0)}, x^{*}\right]$. Selanjutnya dapat diperoleh $f^{\prime}(x)=30 x^{29}$ dan kontinu pada interval $\left[x^{(0)}, x^{*}\right] \subset \mathbb{R} . f(x)$ fungsi naik sejati karena $f^{\prime}(x)=30 x^{29}>0, f^{\prime}(x)$ fungsi naik sejati karena $f^{\prime \prime}(x)=870 x^{28}>0$ dan $f^{\prime}(x) \neq 0$ di setiap $x \in\left[x^{(0)}, x^{*}\right] \subset \mathbb{R}$. Sementara itu, menurut Teorema 3.4 untuk $x \in\left[x^{(0)}, x^{*}\right]$, solusi akan konvergen jika $f(x)$ naik sejati dan $f^{\prime}(x)$ turun sejati atau $f(x)$ turun sejati dan $f^{\prime}(x)$ naik sejati. Jelas bahwa ini tidak dipenuhi oleh persamaan di atas.

\section{Kesimpulan}

Pada makalah ini telah dibahas beberapa teorema yang memberikan syarat cukup kekonvergenan metode Newton-Raphson, yaitu:

(i) Misalkan $f(x)$ mempunyai turunan yang kontinu, $f(x)$ fungsi naik sejati dan $f^{\prime}(x)$ fungsi naik pada interval $\left[x^{*}, x^{(0)}\right]$ dan $f^{\prime}(x) \neq 0$ untuk setiap $x \in$ $\left[x^{*}, x^{(0)}\right]$, maka metode Newton-Raphson dengan tebakan awal $x^{(0)}$ akan konvergen ke $x^{*}$.

(ii) Misalkan $f(x)$ mempunyai turunan yang kontinu, $f(x)$ adalah fungsi turun sejati dan $f^{\prime}(x)$ adalah fungsi turun pada interval $\left[x^{*}, x^{(0)}\right]$ dan $f^{\prime}(x) \neq 0$ untuk setiap $x \in\left[x^{*}, x^{(0)}\right]$, maka metode Newton-Raphson dengan tebakan awal $x^{(0)}$ akan konvergen ke $x^{*}$.

(iii) Jika $f(x)$ mempunyai turunan yang kontinu, dan untuk setiap $x$ yang terletak antara $x^{(0)}$ dan $x^{*}$ berlaku $f^{\prime}(x) \neq 0$ dan $f(x) f^{\prime \prime}(x)>0$, maka metode NewtonRaphson dengan tebakan awal $x^{(0)}$ akan konvergen ke $x^{*}$.

\section{Daftar Pustaka}

[1] Bartle R. G. dan R. S. Donald. 1927. Introduction to Real Analysis. John Willey dan Sons, Inc.. New York.

[2] G. Hendra. 2016. Pengantar Analisis Real. Penerbit ITB. Bandung.

[3] Johan Verbeke dan Ronald Cools. 1995. The Newton-Raphson Method, International Journal of Mathematical Education in Science and Technology, 26(2): $177-193$.

[4] J. M. Ortega dan W. G. Rheinboldt. 1970. Iterative Solution of Nonlinear Equation in Several Variables. Academic Press. New York.

[5] Ralston, A., 1965. A First Course in Numerical Analysis. McGraw-Hill. New York.

[6] Sahid. 2003. Analisis dan Implementasi Metode Newton-Raphson. Prosiding Seminar Nasional hasil Penelitian MIPA dan Pendidikan MIPA UNY 2003, Yogyakarta. Hal. 179 - 197.

[7] Ypma, Tjalling J. 1995. Historical Development of the Newton-Raphson Method. Siam Review. 37(4): 531 - 551. 